\title{
Actions of the 5-hydroxytryptamine 1 receptor agonist sumatriptan on interdigestive gastrointestinal motility in man
}

\author{
J Tack, B Coulie, A Wilmer, T Peeters, J Janssens
}

\begin{abstract}
Background-Pharmacological studies of the enteric nervous system have shown the presence of several subtypes of 5-hydroxytryptamine (5HT) receptor, which might be involved in control of the migrating motor complex.

Aims-To study the effect of sumatriptan, an agonist of enteric neuronal ${ }_{5 H T}$ receptors, on interdigestive motility in man.

Subjects and methods-In 12 healthy subjects, interdigestive motility was recorded manometrically in the upper gastrointestinal tract. In seven subjects blood samples were drawn every 15 minutes for radioimmunoassay of motilin and somatostatin. After two phase $3 \mathrm{~s}$ of the migrating motor complex, $6 \mathrm{mg}$ of sumatriptan was administered subcutaneously. Recording continued until two more phase $3 \mathrm{~s}$ had occurred.
\end{abstract}

Results-Sumatriptan induced a premature phase 3 in the jejunum after a median of 10 (8) minutes. The duration of the migrating motor complex cycle was shortened at the expense of phase 2. After sumatriptan, plasma somatostatin concentrations were reduced and gastric phase 3s were suppressed, although median motilin concentrations and the occurrence of plasma motilin peaks were not affected. Phase $3 s$ of the migrating motor complex preceding sumatriptan were associated with motilin peaks, while phase $3 \mathrm{~s}$ after sumatriptan were not. Furthermore, pretreatment with sumatriptan prevented the induction of a gastric phase 3 by the motilin agonist erythromycin.

Conclusions-Administration of the ${ }_{5 H T_{1 P}}$ receptor agonist sumatriptan induces a premature intestinal phase 3 , suppresses gastric phase $3 \mathrm{~s}$, prevents induction of a gastric phase 3 by erythromycin, and reduces plasma somatostatin concentrations.

(Gut 1998;42:36-41)

Keywords: migrating motor complex; motilin; somatostatin; erythromycin; enteric nervous system

The interdigestive state of the gastrointestinal tract in most mammalian species, including man, is characterised by the presence of a cyclical pattern of motor activity called the migrating motor complex (MMC). ${ }^{12}$ The control of the MMC is incompletely understood.
Evidence has accumulated that enteric neuronal 5-hydroxytryptamine (5HT) receptors are involved in regulation of the MMC in animals and in man..$^{3-7}$ In vitro studies in the guinea pig showed that $5 \mathrm{HT}_{4}$ receptors, $5 \mathrm{HT}_{3}$ receptors, $5 \mathrm{HT}_{1 \mathrm{~A}}$ receptors, and $5 \mathrm{HT}_{1 \mathrm{P}}$ receptors are present on myenteric neurones in the stomach and in the small intestine. ${ }^{8-11}$ Using the selective $5 \mathrm{HT}_{3}$ receptor antagonist ondansetron, we showed that $5 \mathrm{HT}_{3}$ receptors are involved in the initiation of gastric phase 3 motor activity in man. ${ }^{12}$ Lack of suitable ligands precluded a similar study for $5 \mathrm{HT}_{1}$ receptors and for $5 \mathrm{HT}_{4}$ receptors. Recently, however, we showed that sumatriptan, a $5 \mathrm{HT}_{1}$ receptor agonist which is used in the treatment of migraine in man, ${ }^{13}$ is an agonist of $5 \mathrm{HT}_{1 \mathrm{P}}$ receptors on myenteric neurones in the stomach. ${ }^{14}$

We have also shown that administration of sumatriptan in man causes a notable delay in gastric emptying of both solids and liquids. ${ }^{15}$ The present study was undertaken to investigate the effect of sumatriptan on interdigestive gastrointestinal motility and on gastrointestinal hormones in man. We recorded gastrointestinal motor activity in healthy volunteers before and after the administration of sumatriptan. Simultaneously, plasma immunoreactive motilin and somatostatin concentrations were monitored and, finally, the effect of a low dose of the motilin agonist erythromycin ${ }^{16}$ on gastrointestinal motor activity in the presence of sumatriptan was also studied.

In the treatment of migraine, sumatriptan $6 \mathrm{mg}$ is administered subcutaneously, with a bioavailability of $96 \%$. After subcutaneous administration, a plasma peak is reached after 10 minutes, and the mean plasma half life is about two hours. ${ }^{13}$ Sumatriptan does not cross the blood-brain barrier. ${ }^{13}$ In the present study, we used the dose and route of administration of sumatriptan which is applied in the acute treatment of migraine.

\section{Materials and methods}

STUDY SUBJECTS

Twelve healthy volunteers (two women and 10 men; mean age 25.9 (2.8) years) participated in the sumatriptan study. None of the subjects had symptoms or a history of gastrointestinal disease or drug allergies, and none were taking any medication. The control group consisted of 22 sex and age matched healthy volunteers. Informed consent was obtained from each participant. The protocol was approved by the Ethics Committee of the University Hospital. 
RECORDING TECHNIQUE

Recordings of antroduodenojejunal intraluminal pressures were performed using an eight lumen polyvinyl catheter (outer diameter 6 $\mathrm{mm}$ ) with a latex bag at its end that could be filled with mercury. The probe was introduced via the mouth and positioned under fluoroscopic control in such a way that the most distal of the three proximal sensors, which were 3 $\mathrm{cm}$ apart, was located in the antrum at the level of the pylorus or just distal to it. The three other sensors were located in the horizontal part of the duodenum and in the proximal jejunum, respectively at 17,42 , and $67 \mathrm{~cm}$ distal to the antropyloric recording sites. The two remaining catheters were used for filling and emptying the mercury bag. This catheter assembly allowed at least one recording orifice to be kept in the distal antrum during the entire experiment and thus the migrating motor complex was adequately monitored simultaneously in the distal antrum, the duodenum, and the upper jejunum. The recording catheters were continuously perfused with water by means of a low compliance pneumohydraulic infusion pump (Arndorfer Medical Specialties Inc., Greendale, Wisconsin, USA) at a flow rate of $0.4 \mathrm{ml} / \mathrm{min}$, and were connected to external pressure transducers (Siemens Elema 746, Siemens, Iselin, New Jersey, USA). Pressures were recorded on a polygraph (Elema Mingograph 82 , Siemens) using a paper speed of $5 \mathrm{~mm} / \mathrm{s}$.

\section{STUDY DESIGN}

Following an overnight fast of at least 12 hours, the recording probe was introduced as described above and secured to the subject's chin with adhesive tape. In 12 volunteers, gastrointestinal motility was recorded until the passage of two phase $3 \mathrm{~s}$ of the MMC. Ten minutes after the second phase 3 passed at the most distal recording site, $6 \mathrm{mg}$ of sumatriptan (Imitrex, Glaxo Belgium) was administered subcutaneously. This dose has been shown to be safe and effective in the control of migraine. ${ }^{13}$ In nine of the 12 volunteers, motility was recorded until two consecutive phase $3 \mathrm{~s}$ of the MMC had occurred after the administration of sumatriptan. In seven of these nine volunteers, blood samples were also drawn at 15 minute intervals throughout the study to determine motilin and somatostatin concentrations. In the remaining three volunteers, 15 minutes after the administration of sumatriptan, $40 \mathrm{mg}$ of erythromycin lactobionate (Abbott Labs), dissolved in $100 \mathrm{ml}$ normal saline, was infused over 20 minutes via a second intravenous line. Motor activity was continuously recorded until the passage of a phase 3 .

The control group for the study of the effect of sumatriptan on the MMC consisted of 16 volunteers in whom motor activity was recorded with the same technique until four phase $3 \mathrm{~s}$ had occurred. The control group for the study of the interaction between sumatriptan and erythromycin consisted of six volunteers in whom motor activity was recorded with the same technique; the same dose of erythromycin was administered 15 minutes after the passage of a spontaneous phase 3 .
ANALYSIS

Analysis of the recordings of gastroduodenojejunal motor activity was performed by two of the authors (JT and AW) independently. Visual inspection allowed continuous identification of the most distal antral recording site as the catheter that recorded up to three pressure waves per minute (antral waves) just proximal to the catheter that recorded up to 12 contractions per minute (duodenal waves) or to the catheter that exhibited a mixture of antral and duodenal waves. The different phases of the migrating motor complex were identified as described previously. ${ }^{2}{ }^{12} 16$ Whenever possible, the propagation velocity of phase 3 was assessed from the gastric to the duodenal sensor and from the first to the second jejunal sensor.

Plasma motilin and somatostatin concentrations were determined by radioimmunoassay as previously described. ${ }^{17}{ }^{18}$ To determine whether sumatriptan affects basal concentrations of somatostatin or motilin, all concentrations of each hormone before sumatriptan were compared against all concentrations of each hormone after sumatriptan. In addition, the average hormone concentrations for each MMC cycle were assessed for possible differences between each other. In addition, the maximum motilin concentration before sumatriptan was compared with the maximum motilin concentration after sumatriptan. The motilin concentration associated with phase 3 was defined as the motilin concentration measured during phase 3 at its segment of onset or just prior to the onset of phase 3 if no sample was taken during the phase $3 .^{16}{ }^{17}$ To test whether motilin peaks were present at the onset of a phase 3 , the motilin concentrations associated with each phase 3 were compared with the average of all motilin concentrations over the whole recording time and to the average motilin concentrations of each MMC cycle preceding (or following) the phase 3.

The two tailed paired $t$ test was used to determine significant differences between cycle lengths, the velocity of propagation, and the duration of the phase 3. A one population model with repeated measurements on categorical data for time and treatment main effect (Catmod procedure, SAS software) was used to determine whether there was a significant difference between the number of phase $3 \mathrm{~s}$ of MMC starting in the stomach before and after sumatriptan. The unpaired $t$ test was used to compare the number of phase $3 \mathrm{~s}$ originating in the stomach in the control group versus the sumatriptan group. Data on hormone concentrations were analysed by analysis of variance, or Student's paired $t$ test. All values are presented as median (SEM). Differences were considered to be significant at the $5 \%$ level.

\section{Results}

EFFECT OF SUMATRIPTAN ON THE DIFFERENT PHASES OF THE MIGRATING MOTOR COMPLEX In all 12 volunteers, two phase $3 \mathrm{~s}$ before and two phase $3 \mathrm{~s}$ after the administration of sumatriptan were readily identified. In all volunteers, sumatriptan caused a premature 


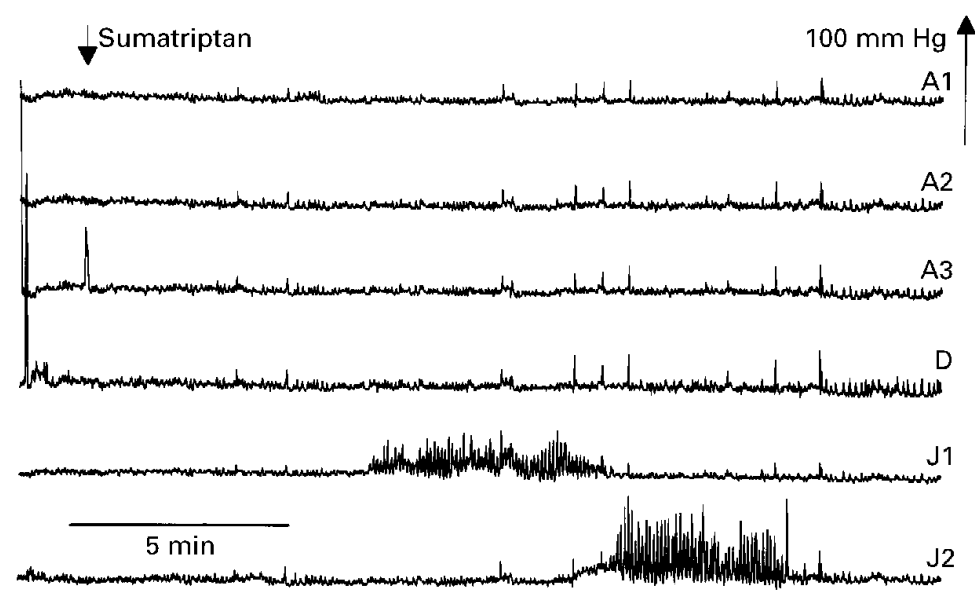

Figure 1 Effect of sumatriptan on upper gastrointestinal motility in a healthy volunteer. $A 1, A 2, A 3$, antral recording sites; $D$, duodenal recording site; $\mathfrak{F 1 , ~} \mathcal{7} 2$, jejunal recording sites.

Table 1 Characteristics of MMC activity before and after administration of sumatriptan in 12 healthy volunteers

\begin{tabular}{lccl}
\hline Variable & Control & Sumatriptan & p Value \\
\hline MMC cycle duration (minutes) & $84.0(10.6)$ & $34.0(6.5)$ & 0.001 \\
Phase 1 duration (minutes) & $20.5(4.8)$ & $17.5(5.0)$ & NS \\
Phase 2 duration (minutes) & $61.7(8.2)$ & $13.0(2.2)$ & 0.0002 \\
Phase 3 duration (minutes) & $5.2(0.7)$ & $5.0(0.5)$ & NS \\
Phase 3 propagation velocity (cm/min) & $5.9(1.1)$ & $5.1(1.0)$ & NS \\
Phase 3, percentage gastric onset & $54 \%(13 / 24)$ & $5 \%(1 / 21)$ & 0.005 \\
\hline
\end{tabular}

Results are expressed as median (SEM).

The duration of the different phases of the MMC were measured during the cycle preceding the administration of sumatriptan and the first cycle after the administration of sumatriptan at the most distal jejunal channel; the propagation velocity of phase 3 was measured at the jejunal level.

Table 2 Plasma concentrations of gastrointestinal hormones (in $\mathrm{pg} / \mathrm{ml}$ ) before and after administration of sumatriptan in seven healthy volunteers

\begin{tabular}{llll}
\hline Variable & Control & Sumatriptan & p Value \\
\hline Median motilin concentration & $309(38)$ & $317(42)$ & NS \\
Peak motilin concentration & $393(46)$ & $403(49)$ & NS \\
Median motilin concentration during MMC cycle & $326(42)$ & $316(44)$ & NS \\
Motilin concentration associated with phase 3 & $376(32)^{\star}$ & $213(23)$ & 0.009 \\
Median somatostatin concentration & $7.5(0.9)$ & $5.6(0.9)$ & 0.005 \\
Median somatostatin concentration during MMC cycle & $6.8(2.2)$ & $5.3(1.7)$ & 0.04 \\
\hline
\end{tabular}

Results are expressed as median (SEM). Median hormone concentrations before and after sumatriptan were calculated from respectively $14.3(1.4)$ and $11.1(1.0)$ samples per subject. The median hormone concentrations during the MMC cycle before and after sumatriptan were calculated from respectively $7.1(0.8)$ and $6.4(1.8)$ samples per subject. ${ }^{\star}$ Significantly different from the motilin level during the MMC cycle before sumatriptan.

phase 3 with jejunal onset after a median interval of 10 (8.2) minutes (fig 1 ). Table 1 summarises the effects of sumatriptan on different phases of the MMC. Sumatriptan shortened MMC cycle length from 84 (10.6) minutes before administration to 34 (6.5) minutes for the first cycle after sumatriptan $(\mathrm{p}=0.001)$ and 51.5 (6.8) minutes for the median of the first and second cycles after sumatriptan $(p=0.002)$. The duration of phase 1 of the MMC cycle was not affected by sumatriptan. In contrast, the duration of phase 2 of the MMC cycle was significantly shortened after sumatriptan. The duration of phase 3 of the MMC cycle, as well as the propagation velocity of the phase $3 \mathrm{~s}$ at the jejunal level, were not affected by sumatriptan. Due to a lack of gastric and duodenal phase $3 \mathrm{~s}$ after sumatriptan (see below), it was not possible to compare the duration of phase 3 at the gastric and duodenal level and the propagation velocity from stomach to duodenum before and after administration of the drug.
EFFECT OF SUMATRIPTAN ON ANTRAL PHASE 3 MOTOR ACTIVITY

In the control group, the first phase 3 of the MMC cycle started at the antral level in 11/16 subjects, the second phase 3 in $8 / 16$, the third phase 3 in 9/16, and the fourth phase 3 in 13/16 subjects. The factor time had no effect on the site of origin of the phase $3 \mathrm{~s}$ in the controls $(\mathrm{p}=0.88)$.

In the sumatriptan group, the first phase 3 of the MMC cycle started from the stomach in $8 / 12$ subjects and the second phase 3 in $5 / 12$ (not significantly different from the control group). The third phase 3 of the MMC cycle, the first after sumatriptan, started at the level of the stomach in $0 / 12$ subjects and the fourth phase 3 in $1 / 9$. In total, $54 \%(13 / 24)$ of the spontaneously occurring phase $3 \mathrm{~s}$ before the administration of sumatriptan started in the stomach, versus $5 \%(1 / 21)$ after the administration of sumatriptan $(\mathrm{p}=0.005$ in comparison with phase $3 \mathrm{~s}$ occurring before sumatriptan; $\mathrm{p}<0.001$ in comparison with the control group).

PLASMA MOTILIN CONCENTRATIONS

An average of 25.4 (1.6) samples (14.3 (1.4) before and 11.1 (1.0) after sumatriptan) were taken in each of the seven volunteers. In these subjects, 9/14 phase 3s before sumatriptan had a gastric origin. For technical reasons, the collecting of plasma samples was stopped prematurely on some occasions. Thus, after sumatriptan, plasma samples continued to be available in all volunteers for the first phase 3 and in $4 / 7$ volunteers for the second phase 3 . Of these, none originated in the stomach.

Table 2 presents data on motilin plasma concentrations before and after sumatriptan. Sumatriptan did not affect basal and peak motilin concentrations: there were no significant differences between the median of all motilin concentrations before and after sumatriptan and between the peak motilin concentrations before and after sumatriptan. The average motilin concentration for the whole MMC cycle was not different before (first MMC cycle) and after (second and third MMC cycle) sumatriptan. The motilin values associated with the phase $3 \mathrm{~s}$ before sumatriptan (376 (32) pg/ml) were significantly different from the median motilin values over the whole recording time $(\mathrm{p}=0.0009)$ and from the median motilin concentrations of the first MMC cycle $(p=0.01)$. In contrast, the motilin values associated with the phase $3 \mathrm{~s}$ after sumatriptan (213 (23) pg/ml) were not significantly different from the median motilin values over the whole recording time $(p=0.08)$ and from the median motilin concentrations of the second and third MMC cycles $(p=0.2)$.

These data show that administration of sumatriptan did not change basal motilin concentrations and did not inhibit normal cyclic increases of plasma motilin concentrations. As illustrated in fig 2, plasma motilin peaks before sumatriptan were associated with the occurrence of gastric phase 3 activity. After sumatriptan, plasma motilin peaks continued to 


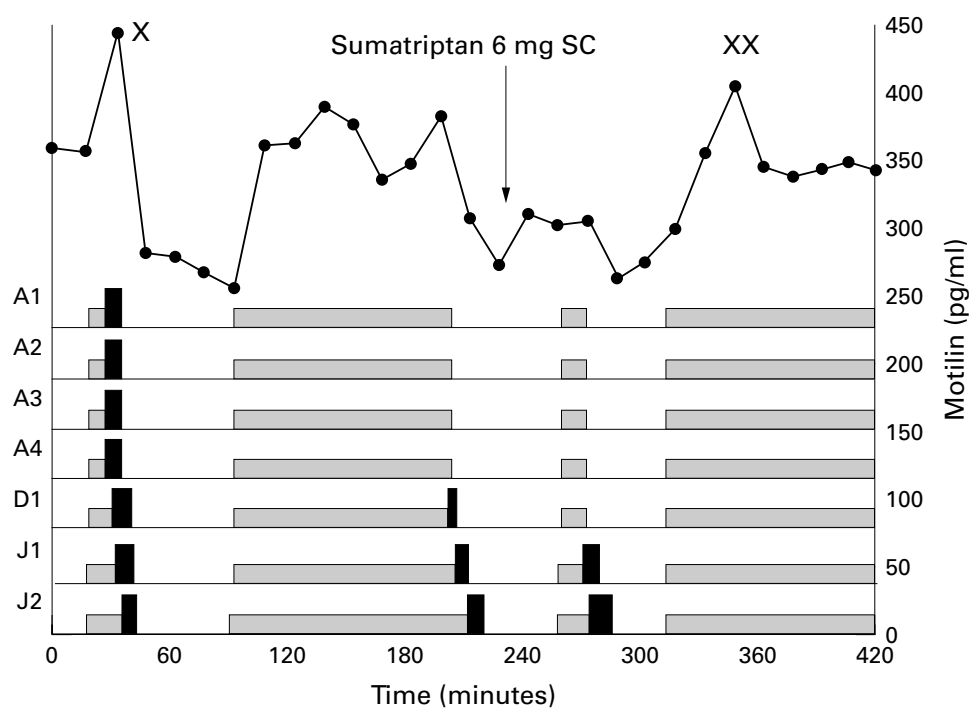

Figure 2 Typical changes of interdigestive motility and its relation to motilin plasma concentrations in a healthy volunteer. The seven lower traces depict schematic representations (flat line $=$ phase 1 ; tinted bars $=$ phase 2 ; black bars $=$ phase 3 ) of the different phases of the MMC in the stomach and the upper small intestine. $A 1, A 2, A 3, A 4$, antral recording sites; $D 1$, duodenal recording site; $\mathfrak{F 1}, \mathfrak{F} 2$, jejunal recording sites. Two spontaneous activity fronts occur, the first of gastric origin and the second of duodenal origin. Administration of sumatriptan induces a premature jejunal activity front. The upper trace depicts motilin plasma concentrations throughout the study. The spontaneously occurring activity front is accompanied by a plasma motilin peak $(x)$. The sumatriptan induced premature jejunal activity front is not accompanied by a plasma motilin peak. After administration of sumatriptan, a plasma motilin peak (xx) is not accompanied by phase 3 activity.

occur, but these were no longer associated with gastric phase 3 activity.

PLASMA SOMATOSTATIN CONCENTRATIONS Somatostatin concentrations were determined on the same samples from which motilin concentrations were measured. Table 2 presents data regarding plasma somatostatin concentrations before and after sumatriptan. Although somatostatin concentrations varied with the MMC cycle, and maximal concentrations were reached during the occurrence of a phase 3, these differences did not reach statistical significance. Sumatriptan significantly

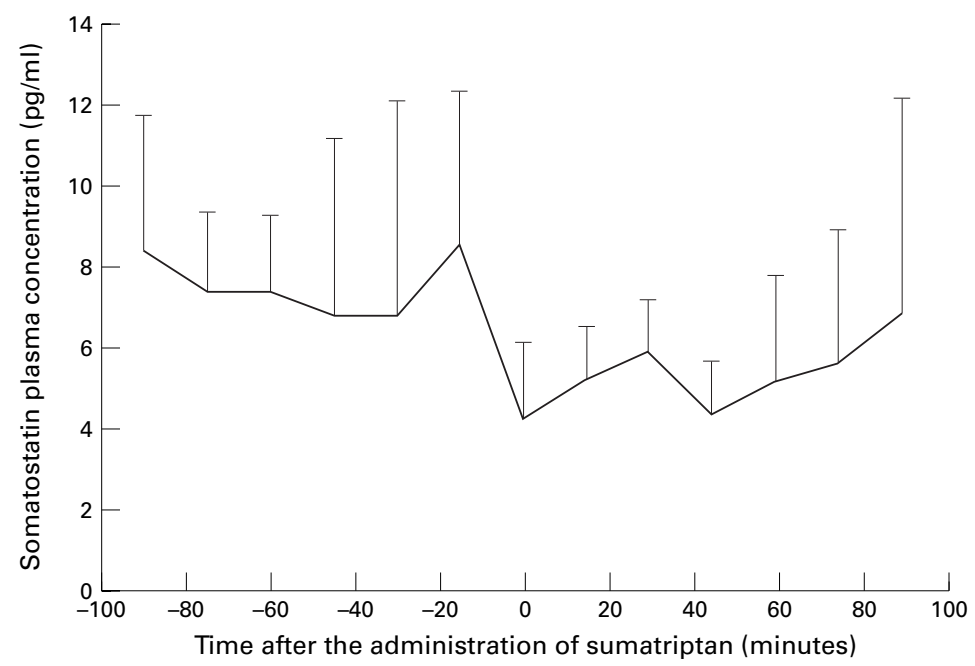

Figure 3 Plasma somatostatin concentrations in seven healthy volunteers at 15 minute intervals before and after sumatriptan $6 \mathrm{mg}$ subcutaneously. The activity front preceding the administration of sumatriptan (at time 15 minutes) is accompanied by a plasma somatostatin peak. After its administration, low plasma somatostatin concentrations are observed, and the sumatriptan induced premature activity front (on average at time 10 minutes) is not accompanied by a plasma peak. decreased basal somatostatin concentrations (7.5 (0.9) versus $5.6(0.8) \mathrm{pg} / \mathrm{ml} ; \mathrm{p}=0.006)$ (fig 3). The average somatostatin concentrations for the first MMC cycle were significantly higher than the average somatostatin concentrations during the second MMC cycle or during both the second and the third MMC cycles $(p=0.03$ for both). The average somatostatin concentration for the whole MMC cycle before sumatriptan was significantly higher than the average somatostatin concentration for the whole MMC cycle after sumatriptan (table 2).

EFFECT OF SUMATRIPTAN ON ERYTHROMYCIN INDUCED PHASE 3 GASTROINTESTINAL MOTILITY In three volunteers, administration of sumatriptan was followed after $4(0.6)$ minutes by a phase 3 of jejunal onset, which lasted for 5 (1) minutes. Fifteen minutes after the administration of sumatriptan, $40 \mathrm{mg}$ of erythromycin was administered intravenously. The next phase 3 of the MMC cycle - of gastric onset in two volunteers and of jejunal onset in one volunteer-occurred 102 (16.2) minutes after the start of the erythromycin infusion. The velocity of propagation at the jejunal level and the duration of this phase 3 were not significantly different from the values for spontaneously occurring phase $3 \mathrm{~s}$ in the same subjects $(7.4(1.3)$ versus $7.9(1.3) \mathrm{cm} /$ minute and 4.5 (1.5) versus $4.7(0.3)$ minutes respectively, NS). In all six controls, a $40 \mathrm{mg}$ dose of erythromycin induced a premature phase 3 with gastric onset after 17.6 (2) minutes. This was significantly shorter than in those who received pretreatment with sumatriptan (17.6 (2) versus 102 (16.2) minutes, $\mathrm{p}=0.02$ ).

\section{Discussion}

The present study has shown that administration of the $5 \mathrm{HT}_{1}$ receptor agonist sumatriptan in the interdigestive state in man induces a premature phase 3 of MMC with jejunal onset and suppresses phase 3 motor activity in the stomach. The MMC cycle length was significantly shortened by the administration of sumatriptan, at the expense of phase 2 . Of all the phase $3 \mathrm{~s}$ recorded preceding the administration of sumatriptan, $54 \%$ started in the stomach. After administration of sumatriptan, only $5 \%$ of phase $3 \mathrm{~s}$ were observed to start in the stomach, a highly significant decrease. Except for the site of initiation, no differences in the duration and velocity of migration of the phase $3 \mathrm{~s}$ were observed before and after sumatriptan.

Several agents are able to induce a premature phase 3 in the interdigestive state in man. Erythromycin and motilin are able to induce a phase 3 which starts in the stomach. ${ }^{16} 1920$ Somatostatin and metenkephalin elicit a phase 3 which starts in the small bowel. ${ }^{18}{ }^{21}$ It has already been shown that sumatriptan is able to influence endocrine secretion in man. ${ }^{22}$ By measuring plasma somatostatin concentrations before and after administration of sumatriptan, we ruled out release of somatostatin as a mechanism by which sumatriptan might induce a premature jejunal phase 3 . Although a release of metenkephalin cannot be entirely discarded 
as a putative mechanism of action, there are several observations which support the hypothesis that sumatriptan is acting on enteric neuronal $5 \mathrm{HT}$ receptors to induce a premature intestinal phase 3 in man. The fact that sumatriptan poorly penetrates the blood-brain barrier argues against a central action. ${ }^{13}$

Evidence has accumulated that enteric neuronal $5 \mathrm{HT}$ receptors are involved in regulation of the small intestinal MMC in animals. Administration of 5HT, or its precursor 5-hydroxytryptophan, decreases MMC periodicity in animals, ${ }^{67}$ whereas administration of neural 5HT receptor antagonists increases MMC periodicity. ${ }^{4}$ Furthermore, selective destruction of enteric serotonergic neurones disrupts the MMC in rats. ${ }^{5}$ The serotonergic effects on MMC periodicity are not altered by sectioning the extrinsic nerve supply to the gut. ${ }^{6}$ In man, the effect of $5 \mathrm{HT}$ on the migrating motor complex has not been studied directly. Selective antagonism of $5 \mathrm{HT}_{3}$ receptors suppresses gastric phase $3 \mathrm{~s}$ in man. ${ }^{12}$ Administration of a selective $5 \mathrm{HT}$ reuptake inhibitor reduced MMC periodicity and increased the propagation velocity of the phase 3 in the jejunum. ${ }^{3}$ Thus, our observation that sumatriptan induces a premature jejunal phase 3 in man is consistent with animal studies which showed shortened intestinal MMC cycles after administration of $5 \mathrm{HT}$ or its analogues. ${ }^{67}$ It is also consistent with the finding that administration of a selective $5 \mathrm{HT}$ reuptake inhibitor in man reduced MMC periodicity in the jejunum. ${ }^{3}$ The latter study showed the involvement of enteric neuronal $5 \mathrm{HT}$ receptors in the control of the intestinal MMC in man; the present study implies that sumatriptan is an agonist of these receptors.

Several subtypes of $5 \mathrm{HT}$ receptor are known. ${ }^{8}$ Of these, $5 \mathrm{HT}_{1 \mathrm{~A}}, 5 \mathrm{HT}_{1 \mathrm{p}}, 5 \mathrm{HT}_{3}$, and $5 \mathrm{HT}_{4}$ receptors have been identified in the enteric nervous system. ${ }^{8-11}$ The therapeutic effect of sumatriptan in migraine is attributed to its action at $5 \mathrm{HT}_{1 \mathrm{D}}$ receptors, but this $5 \mathrm{HT}$ receptor subtype has never been found in the gut. Sumatriptan has little or no affinity at $5 \mathrm{HT}_{3}$ and $5 \mathrm{HT}_{4}$ receptors, but may act as an agonist of $5 \mathrm{HT}_{1 \mathrm{~A}}$ receptors. ${ }^{8}$ In in vitro studies in the guinea pig, we showed that sumatriptan is also an agonist of postsynaptic $5 \mathrm{HT}_{1 \mathrm{P}}$ receptors on enteric neurones. ${ }^{14}$ Furthermore, sumatriptan did not mimic the $5 \mathrm{HT}_{3}$ receptor mediated fast depolarising response or the $5 \mathrm{HT}_{1 \mathrm{~A}}$ receptor mediated hyperpolarising response to $5 \mathrm{HT}^{14}$ The effects of sumatriptan on intestinal motility in man might thus reflect activation of enteric neuronal $5 \mathrm{HT}_{1 \mathrm{P}}$ receptors. Postsynaptic $5 \mathrm{HT}_{1 \mathrm{P}}$ receptors mediate a long lasting depolarisation in a subset of myenteric neurones. ${ }^{911}$ Presynaptic $5 \mathrm{HT}_{1 \mathrm{P}}$ receptors have been shown to inhibit the release of acetylcholine in the small intestine. ${ }^{2324}$ If our observations are indeed attributable to activation of $5 \mathrm{HT}_{1 \mathrm{P}}$ receptors in man, it is unclear whether these are located pre- or postsynaptically. Unfortunately, the lack of selective and safe 5 HT ligands precludes a more detailed pharmacological study in man at present.
Sumatriptan also suppressed phase 3 motor activity in the stomach. Before administration of sumatriptan, the majority of the phase $3 \mathrm{~s}$ originated in the stomach, and were associated with a plasma motilin peak. After sumatriptan, phase $3 \mathrm{~s}$ originated in the small intestine, and were not associated with a plasma motilin peak. Several observations support the hypothesis that, in man, the gastrointestinal peptide motilin is involved in the induction of gastric phase 3. ${ }^{12} 16-18202526$ We have previously shown that suppression of motilin plasma peaks by somatostatin, pancreatic polypeptide, or $5 \mathrm{HT}_{3}$ receptor antagonism also abolishes gastric phase 3, which can be restored by the administration of motilin or the motilin agonist erythromycin. ${ }^{12}{ }^{18} 25$ In the present study, sumatriptan also inhibited the occurrence of gastric phase $3 \mathrm{~s}$ of the MMC cycle. In contrast to pancreatic polypeptide, somatostatin, or $5 \mathrm{HT}_{3}$ receptor antagonism, sumatriptan does not suppress the occurrence of plasma motilin peaks, and administration of the motilin receptor agonist erythromycin fails to induce a gastric phase 3 in the presence of sumatriptan. Thus, it seems that sumatriptan inhibits the action rather than the release of motilin. Motilin and erythromycin are thought to act via the stimulation of receptors on intrinsic cholinergic neurones. ${ }^{27}$ In vitro studies have shown that activation of presynaptic $5 \mathrm{HT}_{1 \mathrm{P}}$ receptors inhibits release of acetylcholine from cholinergic neurones in the stomach and in the small intestine. ${ }^{23}$ One hypothesis might be that sumatriptan acts at presynaptic $5 \mathrm{HT}_{1 \mathrm{P}}$ receptors to inhibit neurotransmitter release from cholinergic neurones that are stimulated by motilin or erythromycin.

While seeking to rule out the release of somatostatin as a mechanism by which sumatriptan affects intestinal motility, we observed a significant inhibition of plasma somatostatin concentrations by sumatriptan. Fasting somatostatin concentrations in the dog are under vagal cholinergic control. ${ }^{28}$ One hypothesis might be that sumatriptan is acting at presynaptic $5 \mathrm{HT}_{1 \mathrm{P}}$ receptors to inhibit neurotransmitter release from cholinergic neurones that innervate the endocrine pancreas. A recent study in the guinea pig in vitro showed the presence of such a pathway, involving presynaptic inhibitory $5 \mathrm{HT}_{1 \mathrm{P}}$ receptors, to the exocrine pancreas. ${ }^{29}$

In conclusion, the present study showed that administration of the $5 \mathrm{HT}_{1}$ receptor agonist sumatriptan in the interdigestive state in man induces a premature phase 3 with jejunal onset. Several studies have shown the involvement of enteric neuronal $5 \mathrm{HT}$ receptors in the control of the intestinal MMC, both in animals and in man. The present study implies that sumatriptan is an agonist of these receptors. Sumatriptan also suppressed phase 3 motor activity in the stomach, without suppression of the occurrence of plasma motilin peaks. Thus, it seems that sumatriptan inhibits the action rather than the release of motilin. This is further supported by the finding that sumatriptan prevented the induction of a premature gastric phase 3 of the MMC by 
the motilin agonist erythromycin. Finally, we also observed that sumatriptan suppresses plasma somatostatin concentrations. The mechanism underlying the effect of sumatriptan on interdigestive motility and plasma concentrations of gastrointestinal hormones is unclear. Based on our in vitro studies, we hypothesise that sumatriptan is acting at enteric neuronal $5 \mathrm{HT}_{1 \mathrm{p}}$ receptors to cause these effects. Confirmation of this hypothesis awaits the availability of suitable ligands.

1 Szurszewksi JH. A migrating electric complex of the canine small intestine. Am f Physiol 1969;217:1757-63.

2 Vantrappen G, Janssens J, Hellemans J, Ghoos Y. The interdigestive motor complex of normal subjects and patients with bacterial overgrowth of the small intestine. $\mathcal{F}$ Clin with bacterial overgrow

3 Gorard DA, Libby GW, Farthing MJG. 5-Hydroxytryptamine and human small intestinal motility: effect of
inhibiting 5-hydroxytryptamine reuptake. Gut 1994;35: inhibiting

4 Ormsbee III HS, Silber DA, Hardy FE. Serotonin regulation of the canine migrating motor comples. F Pharmacol Exp Ther 1984;231:436-40.

5 Piñeiro-Carrero VM, Clench MH, Davis RH, Andres JM, Franzini DA, Mathias JR. Intestinal motility changes in rats after enteric serotonergic neuron destruction. Am $\mathcal{F}$ Physiol 1991;260:G232-9.

6 Ruckebusch Y, Bardon T. Involvement of serotonergic mechanisms in initiation of small intestine cyclic motor events. Dig Dis Sci 1984;29:520-7.

7 Sagrada A, Brancaccio N, Schiavone A. 5-Hydroxytryptamine affects rat migrating myoelectric complexes through different receptor subtypes: evidence from 5-hydroxytryptophan administration. Life Sci 1990;46: 5-hydroxytry $1207-16$.

8 Hoyer D, Clarke DE, Fozard JR, Hartig PR, Martin GR, Mylecharane EJ, et al. International union of pharmacology classification of receptors for 5-hydroxytryptamine (serotonin). Pharmacol Rev 1994;46:157-203.

9 Mawe GM, Branchek T, Gershon MD. Peripheral neural serotonin receptors: Identification and characterization with specific agonists and antagonists. Proc Natl Acad Sci USA 1986;83:9799-803.

$10 \mathrm{Pan} \mathrm{H}$, Galligan JJ. $5 \mathrm{HT}_{1 \mathrm{~A}}$ and $5 \mathrm{HT}_{4}$ receptors mediate inhibition and facilitation of fast synaptic transmission in enteric neurons. Am f Physiol 1994;266:G230-8.

11 Tack JF, Janssens J, Vantrappen G, Wood JD. Actions of 5 -hydroxytryptamine on myenteric neurones in the gastric antrum of the guinea-pig. Am f Physiol 1992;263:G838-46.

12 Wilmer A, Tack J, Coremans G, Janssens J, Peeters T, Vantrappen G. 5-Hydroxytryptamine ${ }_{3}$ receptors are involved in the initiation of gastric phase 3 motor activity in man. Gastroenterology 1993;105:773-8.
13 Dechant KL, Clissold SP. Sumatriptan. A review of its pharmacodynamic and pharmacokinetic properties, and therapeutic efficacy in the acute treatment
cluster headache. Drugs 1992;43:776-98.

14 Vanden Berghe P, Tack J, Coulie B, Janssens J. Sumatriptan is an agonist at $5 \mathrm{HT}_{1 \mathrm{P}}$ receptors on myenteric neurons in the guinea pig gastric antrum [abstract]. Neurogastroenterol Motil 1995;7:291

15 Coulie B, Tack J, Maes B, Geypens B, De Roo M, Janssens J. Sumatriptan, a selective $5 \mathrm{HT}_{1}$ receptor agonist, induces a lag phase for gastric emptying of liquids in humans. $A m \mathcal{F}$ Physiol 1997;272:G902-8.

16 Tack J, Janssens J, Vantrappen G, Peeters TL, Annese V, Depoortere I, et al. Dose-related effect of erythromycin on gastroduodenal motility and plasma motilin levels. Studies in healthy volunteers and in patients with diabetic gastroparesis. Gastroenterology 1991;103:72-9.

17 Bormans V, Peeters TL, Janssens J, Pearle D, Vandeweerd M, Vantrappen G. In man, only activity fronts that originate in the stomach correlate with motilin peaks. Scand 7 Gastroenterol 1987;22:781-4.

18 Peeters TL, Janssens J, Vantrappen G. Somatostatin and the interdigestive migrating motor complex in man. Regul Pept 1983;5:209-17.

19 Tomomasa T, Kuroume T, Arai H, Wakabayashi K, Itoh Z. Erythromycin induces migrating motor complex in human gastrointestinal tract. Dig Dis Sci 1986;31:157-61.

20 Vantrappen GR, Janssens J, Peeters TL, Bloom SR, Christofides MC, Hellemans J. Motilin and the interdigestive migrating motor complex in man. Dig Dis Sci 1979;24: 497-500.

21 Jian R, Janssens J, Vantrappen G, Ceccatelli P. Influence of metenkephalin analogue on motor activity of the gastrointestinal tract. Gastroenterology 1987;93:114-20.

22 Franceschini R, Cataldi A, Garibaldi A, Cianciosi P, Scordamaglia A, Barreca T, et al. The effects of sumatriptan on pituitary secretion in man. Neuropharmacology 1994;33: 235-9.

23 Takaki M, Branchek T, Tamir H, Gershon MD. Specific antagonism of enteric neural serotonin receptors by dipeptides of 5-hydroxytryptophan: evidence that serotonin is a mediator of slow synaptic excitation in the myenteric plexus. F Neurosci 1985;5:1769-78.

24 Mawe GM, Branchek T, Gershon MD. Blockade of 5HT-mediated enteric slow EPSPs by BRL 24924: gastrokinetic effects. Am F Physiol 1989;257:G386-96.

25 Janssens J, Vantrappen G, Peeters TL. The activity front of the migrating motor complex of the human stomach but not of the small intestine is motilin-dependent. Regul Pept 1983;6:363-9.

26 Sarna SK, Chey WY, Condon RE, Dodds WJ, Myers T, Chang TM. Cause-and-effect relationship between motilin and migrating myoelectric complexes. Am f Physiol 1983;245:G277-84.

27 Fox JET. Motilin — an update. Life Sci 1984;35:695-706.

28 Chung SA, Greenberg GR, Diamant NE. Vagal control of fasting somatostatin levels. Neurogastroenterol Motil 1995;7: $73-8$.

29 Kirchgessner AL, Gershon MD. Presynaptic inhibition by serotonin of nerve-mediated secretion of pancreatic amylase. Am f Physiol 1995;268:G339-45. 